\title{
Acute Ilio-Femoral Thrombosis in a Patient with Chronic Infra-renal Inferior Vena Cava Occlusion Treated with Mechanical Thrombectomy Using a Rotational Catheter
}

\author{
Andrea Mangiameli*, Simone Vagnarelli and Cesare Ambrogi
}

San Giovanni Addolorata Hospital, Rome, Italy

\begin{abstract}
Case Report: A 28-year-old man complained acute low-back pain three-day post-appendectomy. Computed tomography revealed thrombosis of both iliac veins and ascending lumbar vein in a patient with chronic occlusion of infra-renal inferior vein cava. Consequent lumbar and intraspinal epidural venous engorgements caused nerve root and thecal sac compression that simulated a spinal stenosis. Complete symptoms resolution was achieved after thrombectomy using a rotational catheter.
\end{abstract}

Keywords: Low-back pain; Deep venous thrombosis; Coagulopathy

\section{Introduction}

Deep Venous Thrombosis (DVT) in young patients below 30 years is an uncommon condition and is usually associated with secondary causes such as systemic coagulopathy, abdominal surgery, tumors, BuddChiari syndrome, infections, congenital or acquired malformation or rarely idiopathic $[1,2]$. The occurrence of DVT associated with minor abdominal surgery involving the abdominal wall or appendix is a very rare event with various and sometimes atypical clinical manifestations. Anomalies of Inferior Vein Cava (IVC) can increase the risk of bilateral ilio-femoral thrombosis $[3,4]$. Historically, medical treatment has been the first line therapy. Surgical therapy has been offered rarely, because of the complexity of such procedures $[5,6]$.

Here we present the case of a 28 -year-old man who presented acute low-back pain three-day post-appendectomy. Computerized Tomography (CT) scan showed thrombosis of bilateral iliac vein and ascending lumbar vein and chronic occlusion of infra-renal inferior vein cava. Consequent lumbar and intraspinal epidural venous engorgements caused nerve root and thecal sac compression that simulated a spinal stenosis $[7,8]$. Complete symptoms resolution was achieved after thrombectomy using a rotational catheter.

\section{Case Report}

A 28-year-old man presented to the emergency room with cramp, mid-abdominal progressive pain, later localized to the right iliac fossa. Pain was associated with nausea, vomiting, anorexia and mild fever. Physical examination revealed a low-grade fever $\left(38^{\circ} \mathrm{C}\right)$, pain on palpation at right lower quadrant (McBurney's sign), and leukocytosis $\left(12 \times 10^{9} / \mathrm{L}\right.$ or $12,000 /$ microliter $)$ with $85 \%$ neutrophils. The ultrasound study showed a small amount of free fluid in the right lower quadrant and tenderness over a non-compressible structure above the iliac vessels, suggestive of acute appendicitis. An open appendectomy was performed without any complications. After three days, the patient complained the onset of low back pain radiating to both thighs. To exclude disc herniation or spondylodiscitis, a lumbar spine MRI without contrast was performed. Axial T2-weighted images showed IVC infra-renal tract hypoplasia with an extensive thrombosis, ascending lumbar vein thrombosis with dilation of the spinal veins and perivascular inflammation signs (Figure 1). A CT scan venography of the abdomen-pelvis revealed chronic occlusion of infra-renal IVC with evidence of organized thrombus and fibrin bands, thrombosis of common iliac veins and left external iliac vein and a welldeveloped collateral pathway through lumbar and azygous, suggestive
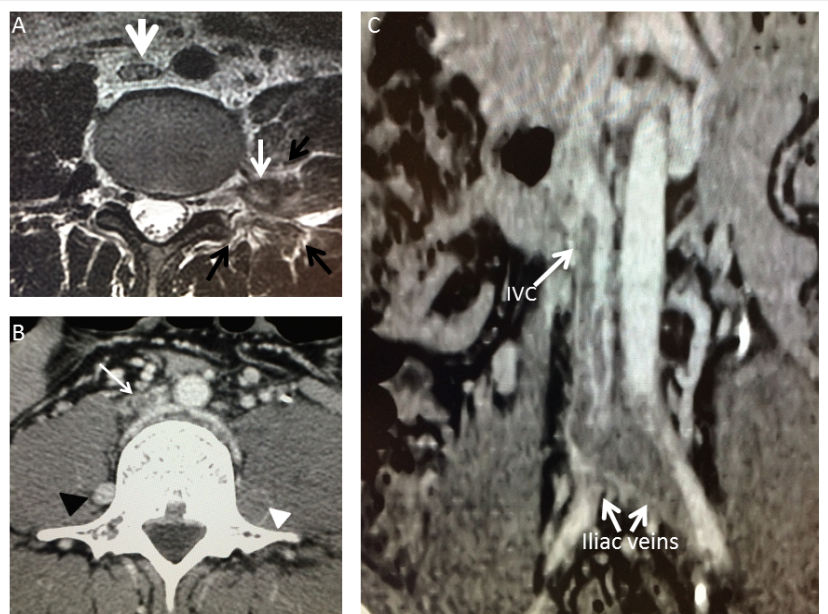

Figure 1: Axial T2-weighted MR image of the lower abdomen showing hypoplasia of the infra-renal tract of the IVC (thick white arrow), which appeared extensively thrombosed; ascending lumbar vein appear thrombosed and dilated (thin white arrow) and accompanying thrombophlebitis with perivascular inflammation sign and engorgement of intraspinal and intraforaminal epidural veins as well as dilated lumbar paravertebral varices (black arrows). CT scan of the abdomen showing: Axial view (L5): extensive thrombosis of IVC with inside organized thrombus and evidence of fibrin bands (white arrow). Right ascending lumbar vein appear dilated but pervious (black arrowhead). Thrombosis of the left ascending lumbar vein (white star) (B). Coronal view: extensive thrombosis of infra-renal IVC, both common iliac veins, left external iliac vein (C).

of long-standing cava obstruction, with left ascending lumbar vein thrombosis (Figure 2). Femoral veins Doppler ultrasound showed marked dilatation of both vessels without evidence of intra-luminal thrombus, but the flow pattern of the external and common iliac veins was monotonous and monophasic, without any respiratory variation,

*Corresponding author: Andrea Mangiameli, Cardiology Department, Ferrarotto Hospital, University of Catania, Italy, Tel: +39-0957436202; Fax: +39-095362429 E-mail: mangiaferla@gmail.com

Received October 03, 2015; Accepted November 02, 2015; Published November 09, 2015

Citation: Mangiameli A, Vagnarelli S, Ambrogi C (2015) Acute llio-Femora Thrombosis in a Patient with Chronic Infra-renal Inferior Vena Cava Occlusion Treated with Mechanical Thrombectomy Using a Rotational Catheter. J Clin Case Rep 5: 651. doi:10.4172/2165-7920.1000651

Copyright: (c) 2015 Mangiameli A, et al. This is an open-access article distributed under the terms of the Creative Commons Attribution License, which permits unrestricted use, distribution, and reproduction in any medium, provided the original author and source are credited. 

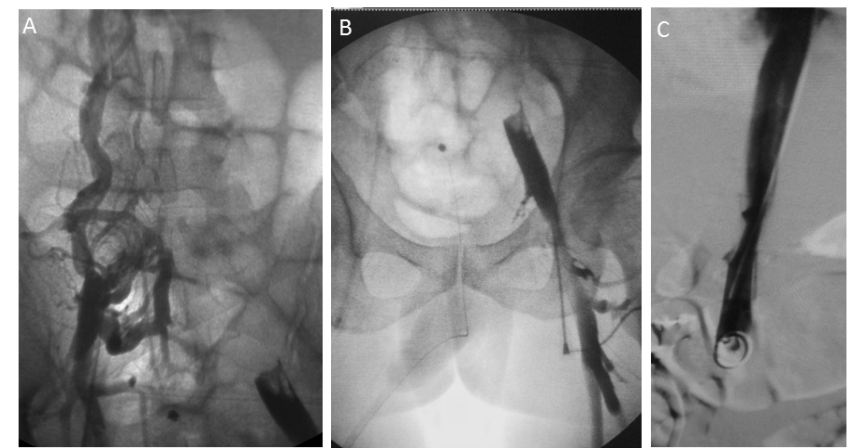

Figure 2: Ascending venogram show: extensive thrombosis of both common iliac veins with dilated right ascending lumbar vein draining in the suprarenal IVC (A-B). Descending venogram show patency of suprarenal IVC (C).
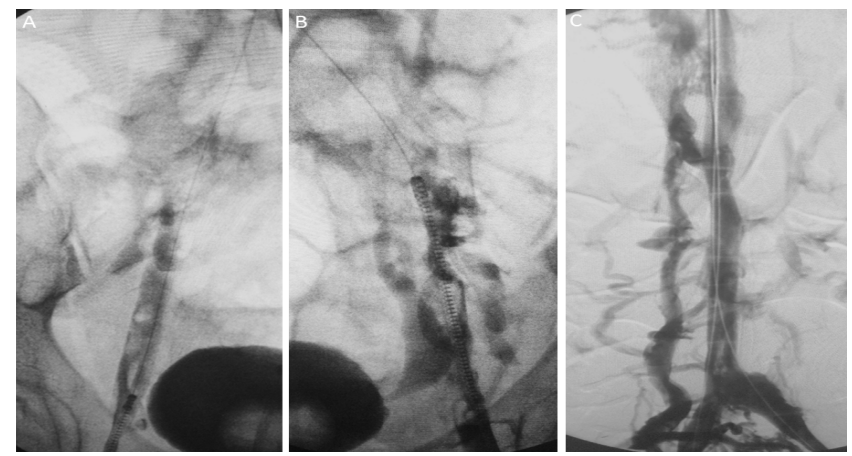

Figure 3: Aspirex $10 \mathrm{Fr}$ in right femoral vein (A) and in iliac femoral vein (B). After mechanical debulking and 72 hours of fibrinolysis, ascending venogram show the full patency of the femoral-iliac-cava axis and of the left lumbar vein (C).

suggestive of iliac occlusion. Under local anesthesia, two 5 Fr sheaths were introduced with the aid of ultrasound in both common femoral veins, venography confirmed the obstruction of the IVC and iliac veins with vein return strictly dependent on the azygous vein continuation (Figure 3) Treatment was started with loco-regional infusion of Urokinase 200.000 U.I. in 15 min through the side arm of the groin sheath, followed by 80.000 U.I./h for 48 hours. Activated clotting time was maintained at $>200$ seconds with heparin. Follow-up venogram at $24 \mathrm{~h}$ and $48 \mathrm{~h}$ showed the non-reperfusion of the iliac-cava axis with the extension of thrombus in the both common femoral veins.

The patient's condition continued to worse in terms of back pain and leg swelling, despite thrombolytic therapy, so an attempt of percutaneous recanalization was performed. After cannulation of both femoral veins with an $11 \mathrm{Fr}$ sheath, vena cava obstruction was forced through using two 0.035 inch hydrophilic guides, one for each sheath. A $4 \mathrm{Fr} \mathrm{V}$ vertebral catheter was advanced over the wire. The 0.035 inch hydrophilic guide-wire was replaced with a 0.018 inch guidewire and then a mechanical thrombectomy device (ASPIREX $10 \mathrm{Fr}$; Straub Medical, Wangs, Switzerland) was introduced and repetitively maneuvered into the thrombi on both femoral veins, both iliac veins, inferior vein cava and left lumbar vein. This over-the-wire catheter system owns a high-speed rotational coil $(40,000-60,000 \mathrm{rpm})$ within the catheter body that creates negative pressure through an L-shaped aspiration port at the catheter tip so that it macerates and removes aspirated thrombus.

After thrombectomy, there was a substantial decrease of thrombus in all treated veins with flow restoration; then balloon angioplasty was performed with two $8 / 60 \mathrm{~mm}$ balloon catheter on bifurcation IVC-iliac veins using kissing-balloon technique and with an $8 / 60 \mathrm{~mm}$ on the left lumbar ascending vein. Follow-up venography showed the presence of minimal residual thrombus with patency of the femoral-iliac-cava axis and partial recanalization of the left lumbar vein, with no evidence of angiographic or clinical embolic complications, then thrombolytic treatment using Urokinase 100.000 U.I./h was continued for 72 hours. Follow-up venogram performed after 72 hours showed the full patency of the femoral-iliac-cava axis and of the left lumbar vein. The patient's symptoms subsided rapidly and he was asymptomatic within a few hours after the thrombectomy procedure. The patient was discharged from the hospital on 4th post-operative day without complications on Coumadin.

\section{Discussion}

IVC malformation is unusual with a $0.3-0.6 \%$ of incidence in general population, but has been reported to occur in $5 \%-16.2 \%$ of young patients presenting with lower limb DVT [3,9]. The classical presentation of lower limb swelling associated with dilated superficial veins occurs only in $50 \%$ of patient with IVC thrombosis; many patients remain asymptomatic, although lower back pain, nephrotic syndrome, hepatic engorgement, cardiac failure and pulmonary embolus have also been described. The low-back pain occurrence was probably relate to acute closure of the ascending lumbar veins and the resulting epidural venous engorgements, because in patient with IVC chronic occlusion, symptoms are closely dependent on the adequacy of the collateral drainage and the ascending lumbar veins plexus is the most important collateral route. These vessels also communicate extensively with vertebral venous network and blood flows can drain through these veins into the azygous or hemiazygous systems.

A possible explanation for thrombosis in our patient was the association of anomalous IVC and the inflamed appendix with associated inflammatory changes producing transient hyper-coagulable states [10]. Conventional treatment of this condition has been directed toward inhibiting clot propagation, thereby reducing the risk of fatal pulmonary embolism. Current treatment options for IVC thrombosis are medical management with anticoagulants and thrombolytic therapy or mechanical with suprarenal vena cava filter placement. Proper anticoagulation therapy, during and after endovenous intervention for acute thrombotic occlusion, is essential to keep the vein patent [11]. The choice of Unfractionated heparin (UFH) has been guided by its ease of administration, rapid onset, easily measurable efficacy and reversibility. Subcutaneous administration of Low-molecular weight heparins LMWHs in a fixed dose is a safe and efficacious alternative to unfractionated heparin in patients with venous thrombosis [12]. Thanks to its excellent pharmacological profile-including long half-life and high anti-Factor Xa/anti-Factor IIa activity ratio- the second-generation LMWH like bemiparin, can be safely used in special categories of patients (children, elderly, patients with renal impairment and congestive heart failure) [13]. Absolute indications for IVC filter placement are contraindication to anticoagulation therapy, recurrent thromboembolic disease despite anticoagulation therapy or complications of anticoagulation, so it was decided to do not implant one, avoiding device related complications.

In our case the rationale behind aggressive management of DVT and the use of mechanical thrombectomy was necessary for the lowback pain worsening, for the evidence of the thrombus extension and in order to avoid post-thrombotic syndrome in a young patient.

\section{Conclusion}

Mechanical debulking of the thrombus has the potential to 
Citation: Mangiameli A, Vagnarelli S, Ambrogi C (2015) Acute llio-Femoral Thrombosis in a Patient with Chronic Infra-renal Inferior Vena Cava Occlusion Treated with Mechanical Thrombectomy Using a Rotational Catheter. J Clin Case Rep 5: 651. doi:10.4172/2165-7920.1000651

significantly improve the thrombolysis rate through lumen vessel restoration and flow reactivation, to increase the contact surface exposed to the thrombolytic agent, allowing it to reach higher concentrations inside the thrombus, making thrombolysis more effective in cases of extensive thrombosis with flow blockage and outflow absence. Moreover mechanical thrombectomy can shorten fibrinolytic infusion duration and avoid fibrinogen and plasminogen depletion related issues, especially in case medical therapy alone appears to be insufficient.

\section{References}

1. Anderson FA, Wheeler HB, Goldberg RJ, Hosmer DW, Patwardhan NA, et al. (1991) Population based perspective of the hospital incidence and case fatality rates of deep vein thrombosis and pulmonary embolism. Worcester DVT study. Arch Intern Med 151: 933-993.

2. Faber SP, O'Donnell TF, Deterling RA, Millan VG, Gallow AD (1984) Clinica implication of acute thrombosis of inferior vena cava. Surg Gynecol Obstet 158: 141-144.

3. Chee YL, Culligan DJ, Watson HG (2001) Inferior vena cava malformation as a risk factor for deep venous thrombosis in the young. $\mathrm{Br} \mathrm{J}$ Haematol 114: 878-880.

4. Gayer G, Luboshitz J, Hertz M, Zissin R, Thaler M, et al. (2003) Congenital anomalies of the inferior vena cava revealed on $C T$ in patients with deep vein thrombosis. AJR Am J Roentgenol 180: 729-732.

5. Jost C.J, Gloviczki P, Cherry K.J, McKusik M.A, Harmsen WS, et al. (2001) Surgical reconstruction of iliofemoral veins and the inferior vena cava for nonmalignant occlusive disease. J Vasc Surg 33: 320-327.

6. Raju S, Fredericks R (1991) Venous Obstruction: an analysis of one hundred thirty-seven cases with hemodynamic, venographic, and clinical correlations. J Vasc Surg 14: 305-313.

7. Dudeck O, Zeile M, Poellinger A, Kluhs L, Ludwig WD et al. (2007) Epidura venous enlargements presenting with intractable lower back pain and sciatica in a patient with absence of the infrarenal inferior vena cava and bilateral deep venous thrombosis. PMID 32: E688-691.

8. Paksoy Y, Gormus N (2004) Epidural venous plexus enlargements presenting with radiculopathy and back pain in patients with inferior vena cava obstruction or occlusion. PMID 29: 2419-2424.

9. .Garcia-Fuster MJ, Forner MJ, Flor-Lorente B, Soler, Campos S (2006) Inferior vena cava malformations and deep venous thrombosis. Rev Esp Cardiol 59 171-175.

10. Libby P, Simon DI (2001) Inflammation and thrombosis: the clot thickens. Circulation 103: 1718-1720.

11. Raju S, Hollis K, Neglen $P$ (2006) Obstructive lesions of the inferior vena cava: clinical features and endovenous treatment. J Vasc Surg 44: 820-827.

12. Monreal M, Lafoz E, Olive A, del Rio L, Vedia C (1994) Comparison of subcutaneous unfractionated heparin with a low molecular weight heparin (Fragmin) in patients with venous thromboembolism and contraindications to coumarin.

13. Ciccone MM, Cortese F, Corbo F, Corrales NE, Al-Momen AK, et al. (2014) Bemiparin, an effective and safe low molecular weight heparin: a review. Vascul Pharmacol 62: 32-37. 